\title{
GEO-SPATIAL ANALYSIS OF NOISE LEVELS IN A UNIVERSITY COMMUNITY
}

\author{
*Iwuji M. C., Igbanny J. U., Ukaegbu K. O. E., Ejiogu C. C., Iwuji K. M., Uyo C. N.
}

Department of Environmental Management, Federal University of Technology Owerri Nigeria

\begin{abstract}
Noise is identified as a disturbance that could induce different behavioural responses. Its exposure for a long period of time has been an issue of concern. Increasing noise levels is not unusual especially with booming developments and innovations in the University environment. This study investigated noise pollution level (NPL) and its spatial distribution within the Campus of Federal University of Technology, Owerri Nigeria. A digital sound level meter-Extech 407730 was used to measure noise level at the sampling points namely, Student affairs unit, SEET head round-about, School park, Senate round-about and FUTO market designated as SP1,SP2,SP3,SP4 and SP5 respectively. A global positioning system (GPS)NAVA 300 was used to record the GPS coordinates of the sampling noise hotspots in the university community. The Arc GIS software was used to assess the geospatial mapping and distribution of noise within the study areas. Results revealed that the noise levels in the school campus reached a peak of $75.7 \mathrm{~dB}(\mathrm{~A})$ in FUTO market on day 4 during the hours of $12 \mathrm{pm}-$ Ipm. Results of geospatial mapping of the noise level in the study area also revealed that noise level exceeds the maximum permissible limit ranging from $40 \mathrm{~dB}(A)$ to $50 \mathrm{~dB}(A)$. Therefore, it was recommended that public enlightenment programs such as workshops and seminars on the health hazards connected with noise pollution within the campus should be held regularly, also, control of noise through the use of sound proof doors, walls, and ceilings that can be installed while erecting buildings within the university community.
\end{abstract}

KEYWORDS: geo-spatial analysis, noise pollution, permissible level, university community

\section{INTRODUCTION}

Noise is arguably the most widespread and least controlled environmental pollutant (Anomohanran, 2013). Noise has gained recognition as unwanted and intrusive even from the Roman era. The Industrial Revolution and the consequent rise of cities are factors believed to have exacerbated noise pollution to current levels, with no abatement (Oyedepo, 2013 \& Bahadori, 2013). According to Nwafor and Menkiti (2015), noise can be an unpleasant sensation since what is music to one's ear might be noise to someone else. Any sound that interferes with hearing or causes stress is termed noise pollution. World Health Organization in 2015, reported that "an estimated 1.1 billion teenagers and young adults risk hearing loss resulting from unsafe use of personal audio devices, such as smart phones, as well as exposure to unsafe sound levels at noisy entertainment venues such as nightclubs, bars and sporting events".

Noise pollution is a modern plague caused by the outrageous level of unsolicited sound in the environment leading to pain. Goines and Hagler, (2007), Kamel, (2008) in their studies have revealed noise sources as coming from vehicular transportation and Airports. Narender and 
Davar, (2004), Wiebe, (2012), Konstantinos, (2012), Song, Li and Wu, (2016) in their studies also reiterated that a number of noise pollution sources include, road traffic noise, air craft, railroads, construction noise, industrial noise, domestic noise from home appliances, plumbing work, power generating sets, air conditioners, boilers, fans, etc, and noise from consumer products such as kitchen appliances, vacuum cleaners, washing machine, mixer, juicer, etc.) (Omubo-Pepple et al., 2010). Spatial distribution of noise pollution is a major problem for both developed and developing countries like Nigeria (Kluijver and Stoter, 2003: Obiefuna et al., 2013). It has become almost impossible to completely avoid noise in University campuses in Nigeria such as the Federal University of Technology, Owerri which are booming with infrastructural developments and various innovations (Abel, 2015). Exposure to excessive noise in an environment has been linked to increased arterial hypertension, myocardial infarction, and other stress related health outcomes; like sleep apnea. These can affect behavior and mental health (Basrur, 2000). These resultant behaviors have a negative impact on students' life generally making it difficult for them to perform optimally in their academics.

The aim of this study is therefore to analyze the noise levels at various locations within the Federal University of Technology, Owerri using Geographic Information System (GIS). According to De Muer and Botteldooren (2003), noise is mapped to display the spatiotemporal distribution in the studied environment. This study mapped the spatial distribution of noise using the ArcGIS Inverse Distance Weighted Model (IDW). The objectives include: Obtaining sound levels of selected areas within the school campus, Compare the primary data obtained with existing environmental regulatory standards, andgenerate a noise map of the school campus using geo-spatial techniques.

\section{MATERIALS AND METHOD}

\section{Description of Study Area}

The Federal University of Technology, Owerri (F.U.T.O), prided as a premier Federal University of Technology in the South East and South West parts of Nigeria, was established in 1980. The University which operates a mono-campus structure is located in Owerri West Local Government Area, Southeast Nigeria and is bounded by four communities - Obinze, Eziobodo, Umuchima and Ihiagwa. Other autonomous communities and homesteads that surround the study area include Umuoma, Nekede, Avu, Okolochi, Obibiezena and Emeabiam. These communities all contributed land acquired for the establishment of the university. The campus occupies an area of about 4,048 hectares, housing eight (10) schools with over forty (40) departments, and a students' population of over 22,000. The popular Otamiri River traverses the campus from North to South adoring the site with its accompanying lush vegetation (See figure 1). 


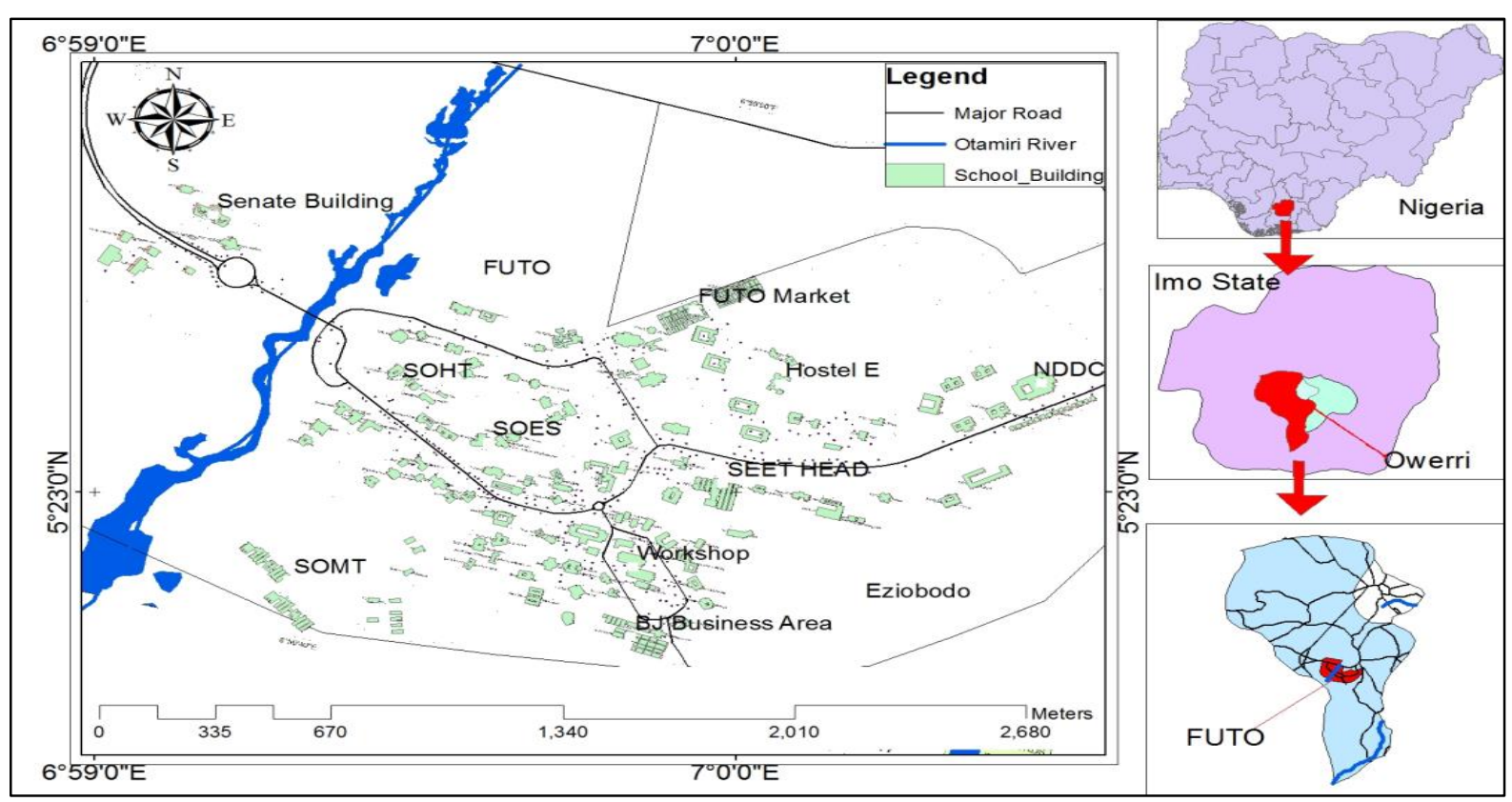

Figure 1: Location of the Study Area

\section{Types of Data}

Primary data used for the research was the Geographic coordinate data comprising the coordinates (altitude, latitude and longitude) of the selected sites which were obtained using a Global Positioning System (GPS) NAVA 300 receiver. While noise level in the selected locations was obtained using an Extech 407730 noise level meter.

\section{METHOD OF DATA COLLECTION}

Noise levels within the sampled locations were measured in-situ. This method involved a continuous (real time) monitoring, in which noise data was automatically transmitted and saved into the database of the monitoring device (Yilmaz \& Hocanli, 2006, Kanjo, 2010 \& Zimmerman \& Robson, 2011). The results were recorded in the field note. The monitoring periods at each sampling site were morning, afternoon and evening for a period of five (5) working days which are peak periods of academic and socioeconomic activities within the campus. Geo-referenced coordinates of each sampling location were taken with the use of a handheld GPS device. The GPS values were also recorded and converted from degrees, minutes and seconds to decimal degrees.

A digital sound level meter with detection range of 40-130 dB was used for measuring sound levels at the various sampling points. Care was taken to ensure that barriers and surfaces capable of bouncing sound waves were avoided. The noise levels were recorded in decibels $(\mathrm{dB})$. All readings are presented in Tables.

\section{Sampling Points}

Sampling code was used and the sample points were coded as follows:

Student affairs unit. SP1

SEET head round-about. SP2 
School Park.......................... SP3

Senate round-about.................. SP4

FUTO market......................... SP5

*Note: SP - Sampling Point

Data was collected in the morning (8:00am - 9:00am), afternoon (12:00pm - 1:00pm) and evening (4:00pm $-5: 00 \mathrm{pm})$ hours from the various points within the school campus. The points purposefully targeted noise hotspots on campus including; the campus bus park, School of Engineering and Engineering Technology (SEET) area, the school mini markets within campus hostels, the old registry business area and senate building area. Intensity of activities, road network / traffic intensity and peak periods of activities were considerations for choosing sampling points.

\section{Techniques of Data Analysis}

Data collected from the sampling sites were compared with relevant standards. Overall morning, afternoon and evening hour-mean values of measured noise level for each day in all the locations was calculated as the mean of the values for the sampling sites.

\section{The tool of Data Analysis}

Software used for the analysis of the obtained data includes; Microsoft Office Word 2016, Microsoft Office Excel 2016 and ArcGIS 10.2.

\section{RESULTS AND DISCUSSIONS}

Table 1: Daily Mean Noise Level Values at Sample Points

\begin{tabular}{llllll}
\hline POINT & DAY & DAY & DAY & DAY & DAY \\
& $\mathbf{1}(\mathbf{d B})$ & $\mathbf{2}(\mathbf{d B})$ & $\mathbf{3}(\mathbf{d B})$ & $\mathbf{4}(\mathbf{d B})$ & $\mathbf{5}(\mathbf{d B})$ \\
\hline School Park & 66.8 & 58.2 & 62.6 & 57.9 & 64.1 \\
SEET Round-about & 68.4 & 68.1 & 66.9 & 65.8 & 61.3 \\
FUTO Market & 70.8 & 67.4 & 65.3 & 73.9 & 67.6 \\
Senate Round-about & 52 & 50.4 & 49.5 & 51.2 & 48.8 \\
Students' Affairs Unit & 64.9 & 62.4 & 51.7 & 60.5 & 60.8 \\
\hline
\end{tabular}

From Table 1, it can be observed that senate round-about recorded the least level of noise throughout the days. This can be attributed to its location around the school senate, a low activity zone as compared with other sample locations. Owners of business centres in FUTO market acknowledged that the noise levels recorded there would have been reduced if generators were properly serviced and maintained overtime. This flaw leads to air and noise pollution in the area. From the table it is observable that the sample points recorded higher noise levels on day 1 as against other days. This may not be unconnected with the fact that day 1 was a Monday and as the first day of the week academic and vehicular activities usually witness a surge. Observation of table 1 shows that activities within the school campus generally reduced as the week proceeded to day 5, Friday. Figure 2 is Multiple Bar Chart Representation of the Daily Mean Noise Level Values at the Sample Points while figure 3 
Is a representation of 5-Day Noise Level Average of Sample points?

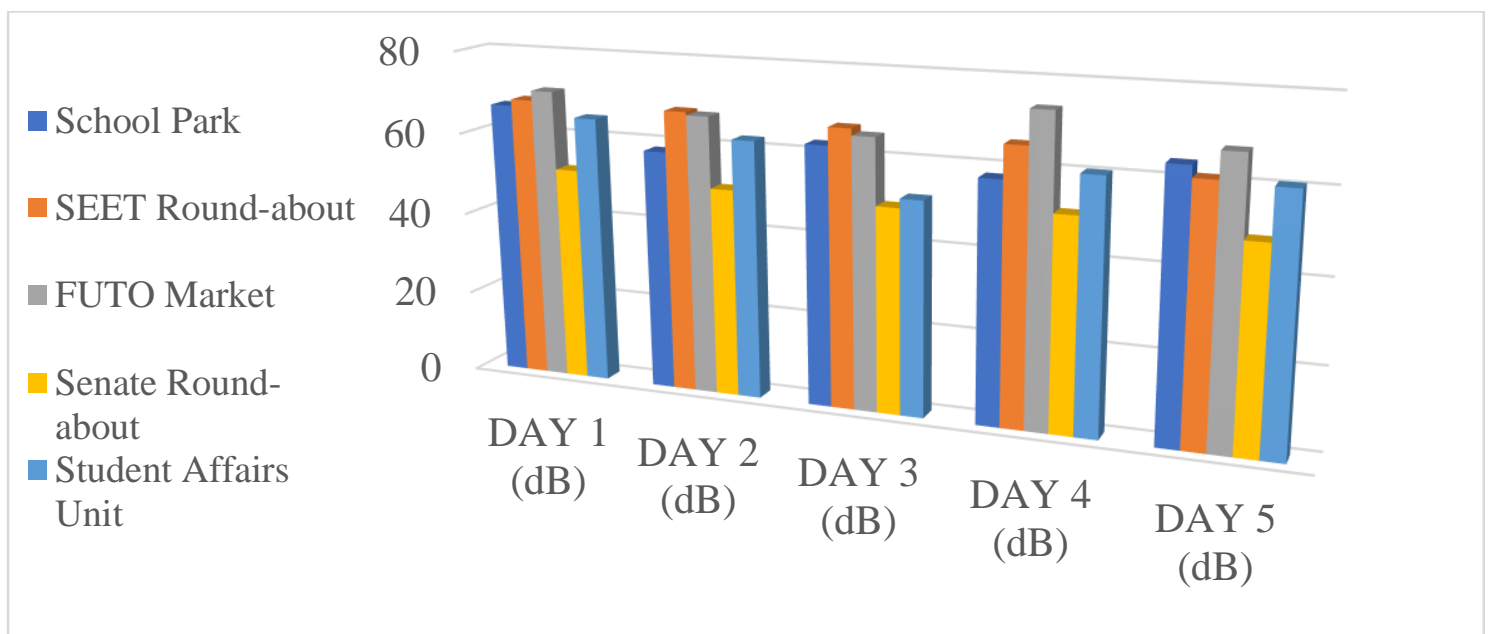

Figure 2: Multiple Bar Chart Representation of the Daily Mean Noise Level Values at Sample Points.

\section{DAYS NOISE LEVEL AVERAGE (dBA)}

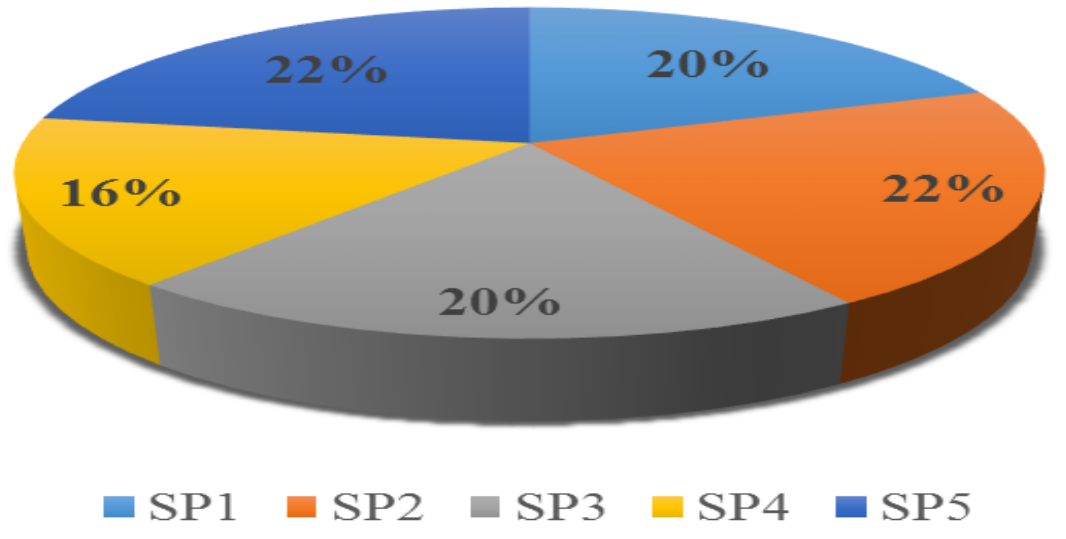

\section{Figure 3: Pie Chart Representation of 5-Day Noise Level Average of Sample Points}

Comparison of the 5 days' noise level average at the different sampling points shows that noise levels were least at SP4 and highest at SP5 and SP2. Figures $4-8$ are 2D models of the University campus showing a colour-coded representation of the noise levels generated for the five days using ArcGIS 10.2. 


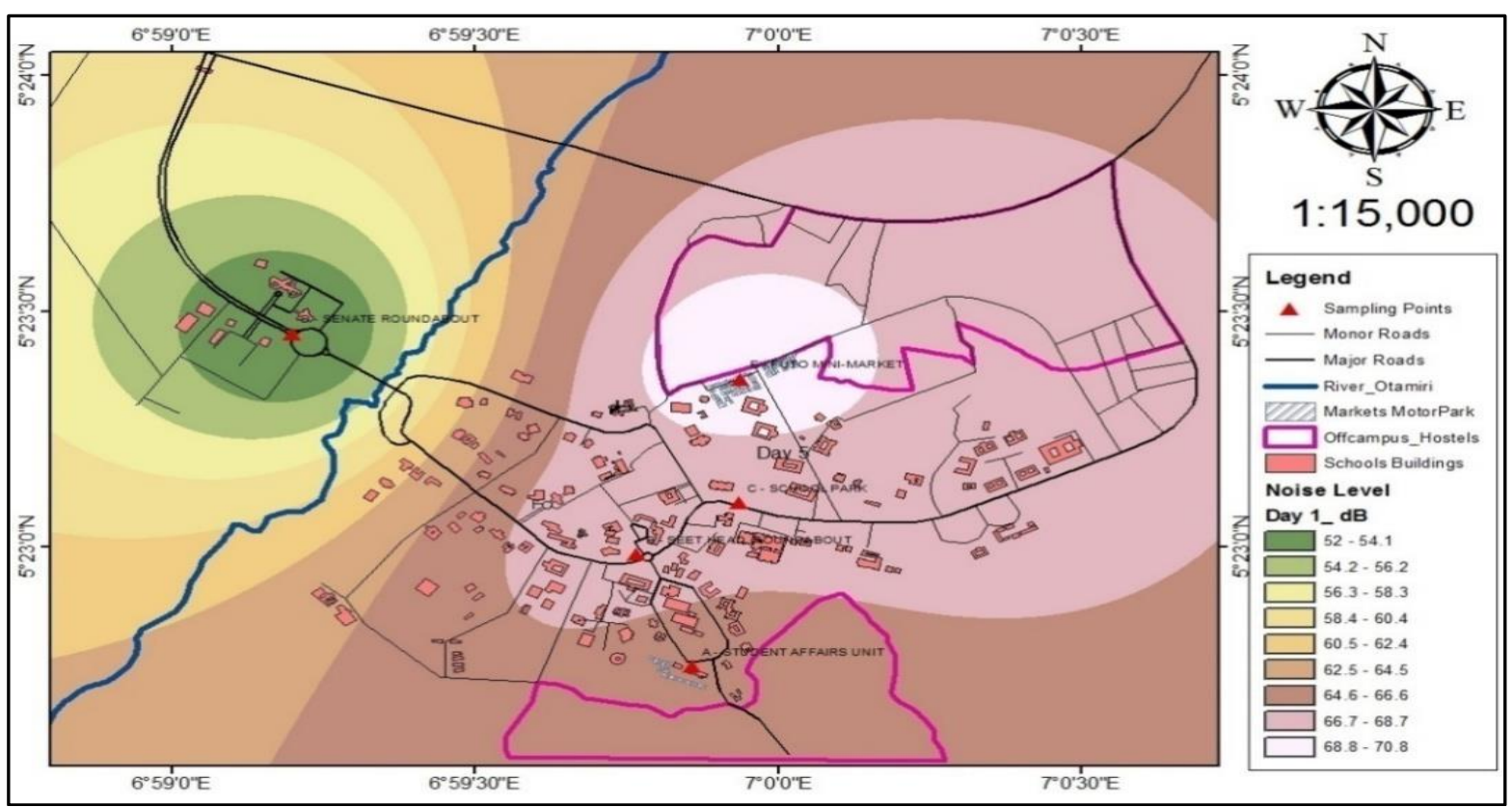

Figure 4: 2-D Map Showing Noise Level Variations at the Sample Points for Day 1

Figure 4 gives a pictorial view of the noise variations within the campus for day 1 in which SP4 exhibited low levels of noise which is denoted with dark green colour. SP5 is located within the white region with levels from $68.8 \mathrm{dBA}-70.8 \mathrm{dBA}$. SP2, and SP3 are located within the pink region depicting their similarities in noise levels while SP1 is located within the dark brown region.

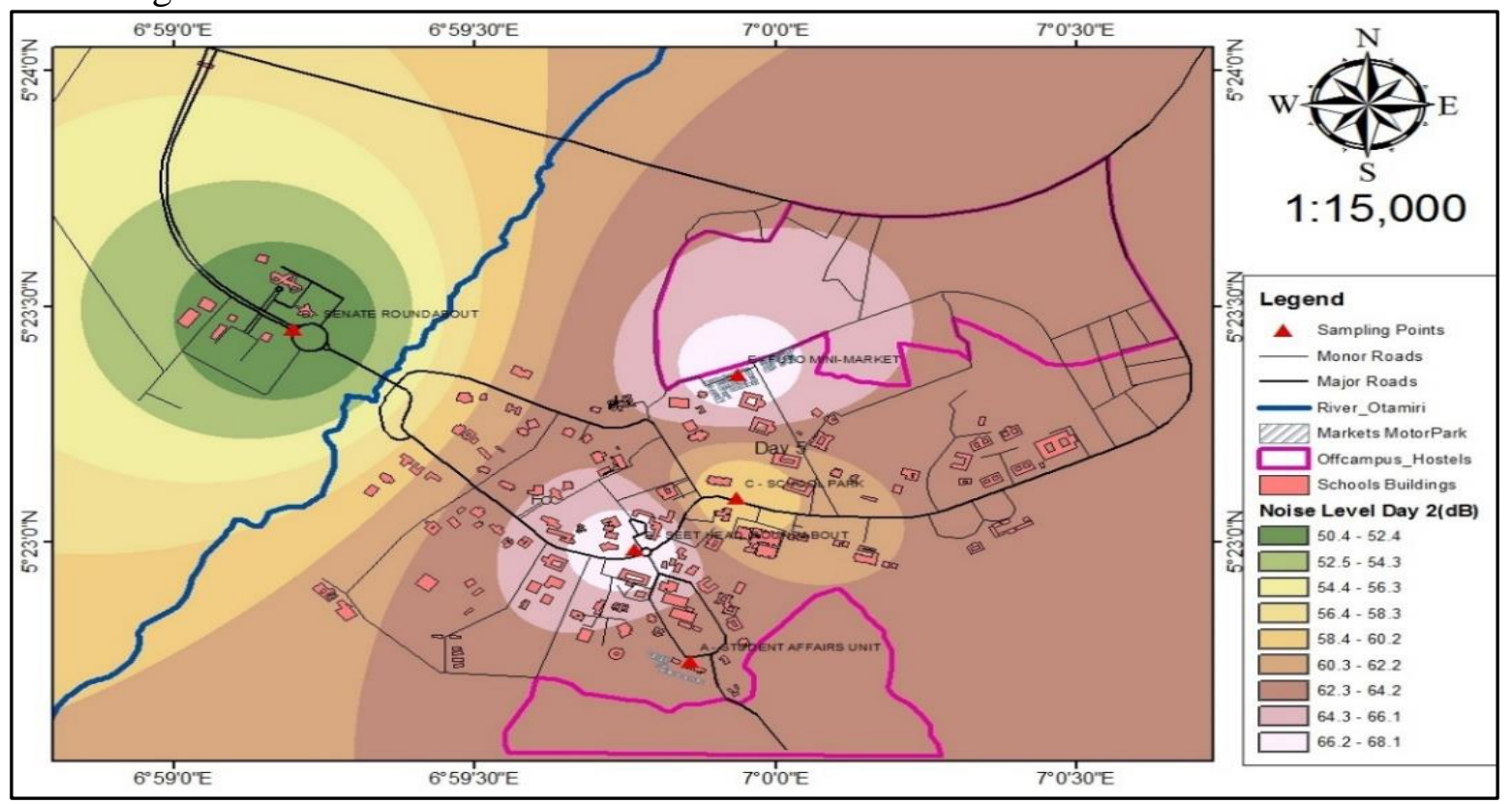

Figure 5: 2-D Map Showing Noise Level Variations at the Sample Points for Day 2

Figure 5 gives a pictorial view of the noise variations within campus for day 2 in which SP4 exhibited low levels of noise denoted with dark green colour. SP5 and SP2 are located within the white region with levels from $68.8 \mathrm{dBA}-70.8 \mathrm{dBA}$. SP3 is located within the light brown 
region depicting their similarities in noise levels while SP1 still maintains its location within the dark brown region. This map depicts increased noise levels.

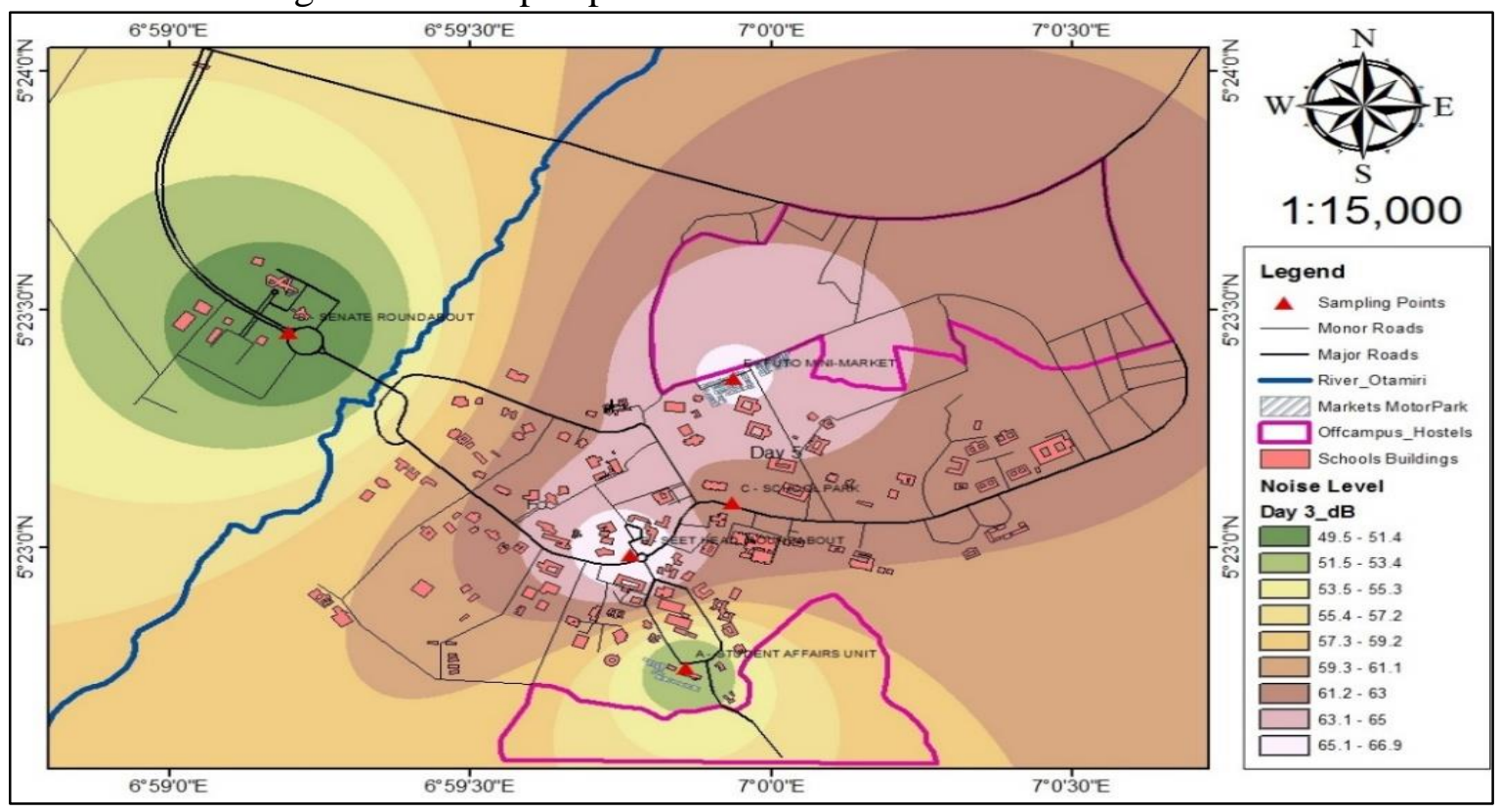

Figure 6: 2-D Map Showing Noise Level Variations at the Sample Points for Day 3

Figure 6 gives a pictorial view of the noise variations within campus for day 3 in which SP1 and SP4 are found to be within the green colour range. SP2 and SP5 still maintain values within the white region. SP3 is located within the dark brown region. SP1 and SP4 fall within the ranges of $49.5-53.4 \mathrm{dBA}$ while SP2 and SP5 maintain similar noise values within $65.3-$ $66.9 \mathrm{dBA}$.

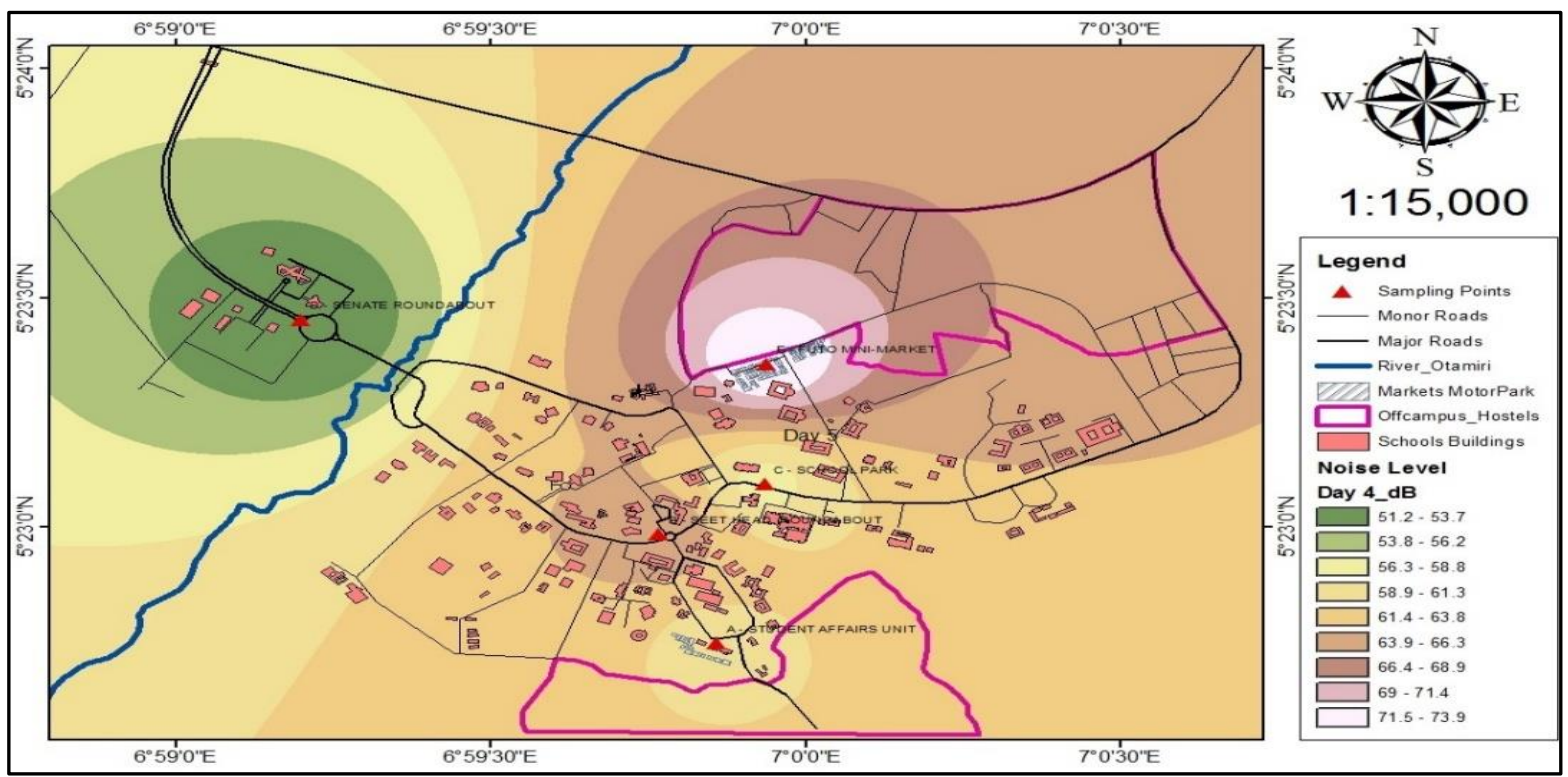

Figure 7: 2-D Map Showing Noise Level Variations at the Sample Points for Day 4

Figure 7 gives a pictorial view of the noise variation within campus for day 4 where SP4 remains in its green colour zone. SP5 is located within the white region. 
$\mathrm{SP} 2$ is located in the light brown region with noise level values above 63.9dBA. SP1 and SP3 are within noise levels of $56.3-63.6 \mathrm{dBA}$.

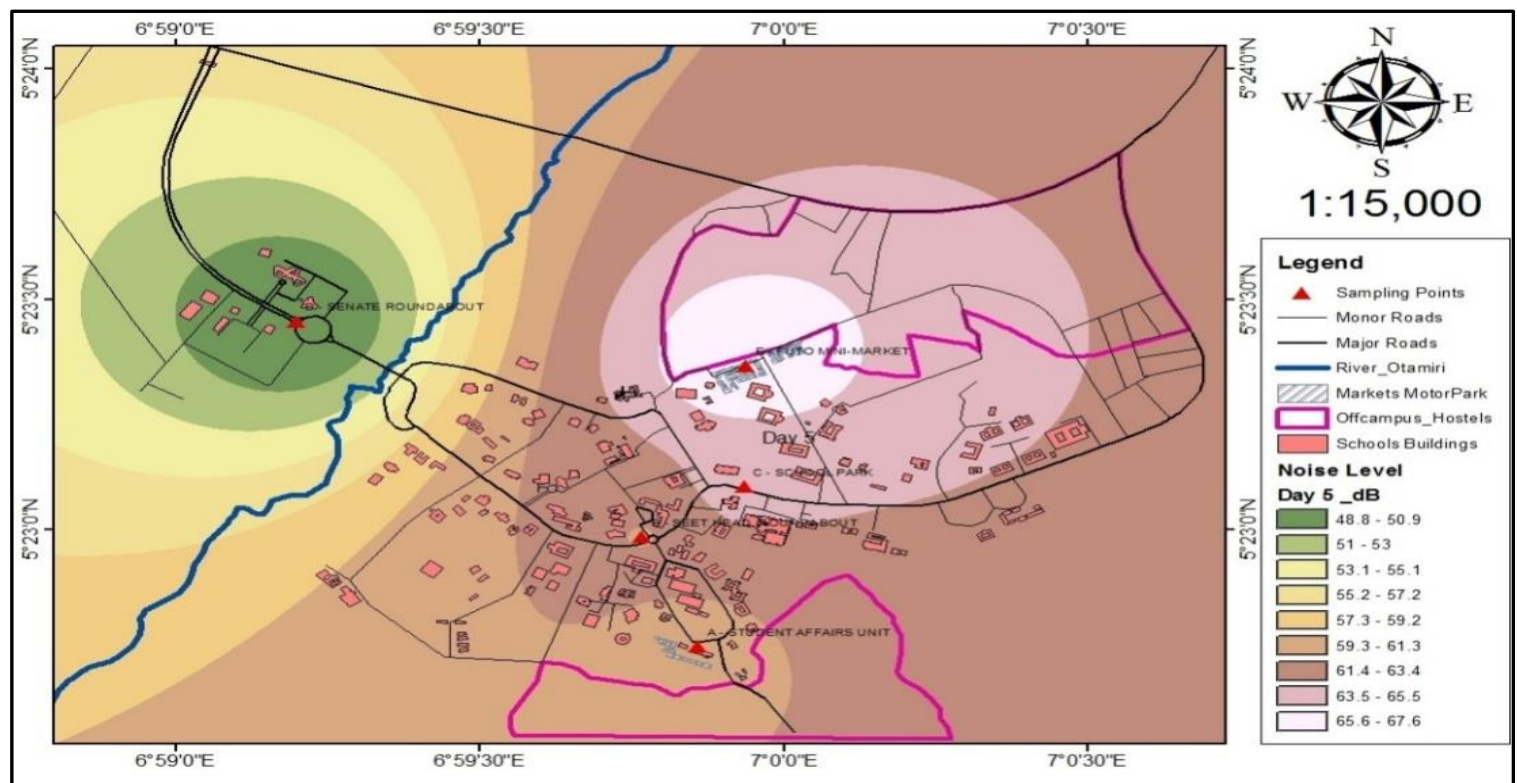

Figure 8: 2-D Map Showing Noise Level Variations at the Sample Points for Day 5

Figure 8 gives a pictorial view of the noise variations within campus for day 5 .

SP4 and SP5 maintain their noise levels within the green and white zones respectively. SP3 is located within the pink region. SP2 is located within the dark brown region and SP1 is located within the light brown region. SP1, SP2, SP3, SP4 and SP5 are in one way or the other characterized with some level of commercial and/or vehicular activities as displayed in the Table 2:

Table 2: Table Showing the Predominant Activity in Each Sample Point

\begin{tabular}{ll}
\hline SAMPLE POINT & PREDOMINANT ACTIVITY \\
\hline SP1 & Vehicular activity (e.g. horning of cars, buses and motorcycles, etc.) \\
& and running generator sets. \\
SP2 & Vehicular activity (e.g. horning of cars, buses and motorcycles, etc.) \\
SP3 & Vehicular activity (e.g. horning of cars, buses and motorcycles, etc.) \\
& and running generator sets. \\
SP4 & Vehicular activity (e.g. horning of cars, buses and motorcycles etc.) \\
SP5 & Vehicular activity (e.g. horning of cars, buses and motorcycles etc.) \\
& and running generator sets. \\
\hline
\end{tabular}

The permissible noise level stipulated for industrial, commercial and traffic areas is $75 \mathrm{~dB}(\mathrm{~A})$. NESREA (2009) on the other hand stipulates a permissible limit of $70 \mathrm{~dB}(\mathrm{~A})$ for the general environment, irrespective of activity. A comparison of these global and national standards with the obtained sample point values is shown in Table 3. 
Table 3: Table Showing the Daily Mean Noise Levels for the Sampling Points and WHO and NESREA Limits

\begin{tabular}{ll}
\hline SP & NOISE LEVEL (dBA) \\
\hline SP1 & 60.06 \\
SP2 & 66.1 \\
SP3 & 61.9 \\
SP4 & 50.38 \\
SP5 & 69 \\
WHO & 75 \\
NESREA & 70 \\
\hline
\end{tabular}

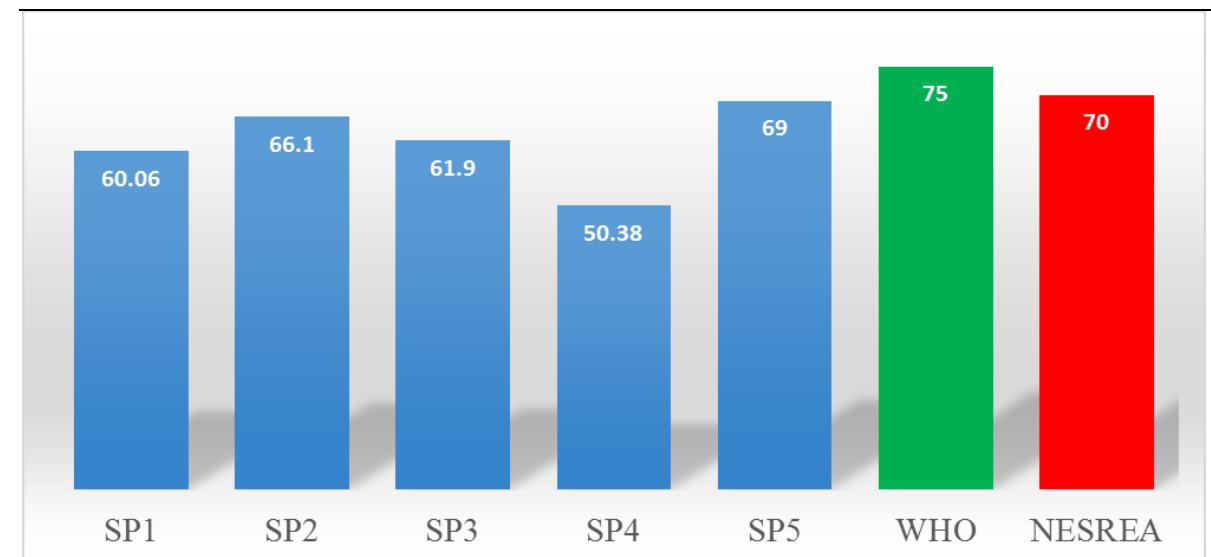

Figure 9: Bar Chart Showing the Comparison of Obtained Values with WHO and NESREA Limits

According to figure 9, although a noise level of $69 \mathrm{~dB}(\mathrm{~A})$ was recorded at SP5, the obtained values concerning nature of activity are within WHO and NESREA permissible limits for traffic, commercial, industrial and general environment respectively. However according to Debnath, et al. (2012), the permissible noise level (outdoor) in an educational institute is 55 $\mathrm{dB}(\mathrm{A})$ and below. In this regard, we can analyze the suitability of the school campus for optimal academic performance using the obtained values.

Given that $X=55 \mathrm{~dB}(\mathrm{~A})$ 


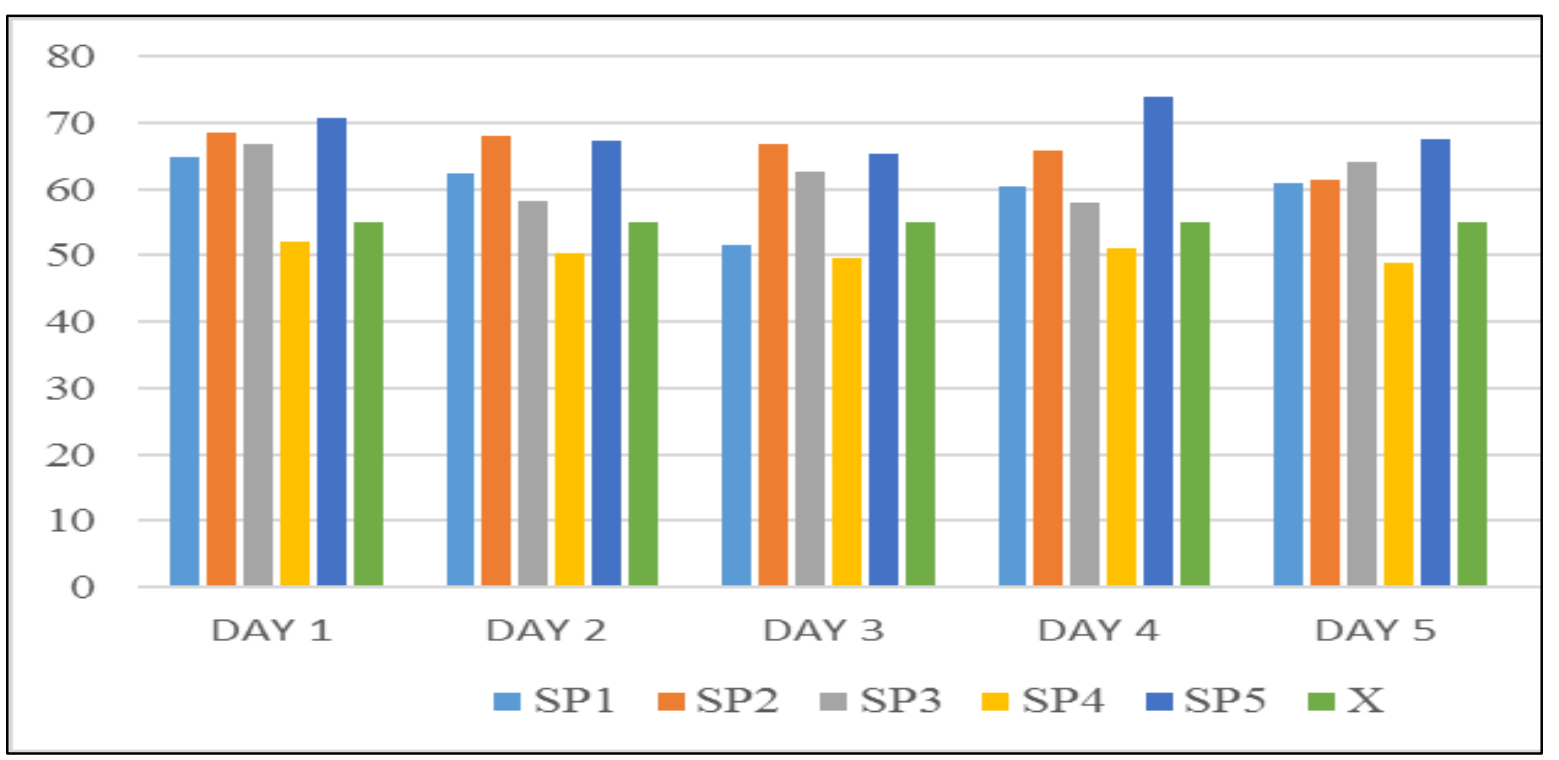

Figure 10: Comparison of Obtained Value with Permissible Noise Level in an Educational Institute

From figure 10, it can be deduced that the level of noise in the selected sample points of the school campus is far beyond the confinements for safe hearing with SP5 climaxing as high as $73.9 \mathrm{~dB}(\mathrm{~A})$ with a difference of $18.9 \mathrm{~dB}(\mathrm{~A})$. From these analyses it can be inferred that the safest area for learning is at SP4.

\section{CONCLUSION AND RECOMMENDATIONS}

Measurement of noise in the selected hotspots within the University campus, shows that noise pollution is present. Although all sample points exceed the tolerance level of noise pollution within the school except for the senate roundabout, the school mini market and SEET Head roundabout; an indication that the surrounding is not conducive for teaching and learning experience. These noise levels can be largely attributed to the proliferation of generating sets and vehicular activities. This study revealed that Senate roundabout maintained noise levels of $51.2-53.7 \mathrm{dBA}$ throughout the five days. FUTO market maintained noise levels of $71.5-$ 73.9dBA throughout the five days. SEET head roundabout and the school park exhibited similar noise levels in day 1 (pink colour). SEET head roundabout and FUTO market exhibited similar noise levels in day 2 and day 3 (white colour). The student affairs and school park exhibited similar noise levels in day 4 (yellow colour). The level of noise within the campus is mainly attributable to the amount of vehicular and commercial activities within the campus.

It is recommended that noise reduction can be achieved by installing soundproof doors, walls and ceilings while erecting school buildings. High-risk noise areas should be effectively identified and avoided to maintain silence within the campus. The importance of a safe academic environment cannot be overemphasized; therefore, the school management is encouraged to conduct noise level analysis of the campus routinely. Generators and other types of machinery should be regularly maintained to ensure that they do not contribute more noise than is necessary in the study area. 


\section{REFERENCES}

Abel, A. A., (2015): Urban noise pollution in Nigerian cities: Imperatives for abatement. British Journal of Applied Science and Technology, Article No. BJAST.18466

Anomohanran, O., (2013): Evaluation of environmental noise in Abuja, the capital city of Nigeria. International Journal of Research and Reviews in Applied Sciences, Volume 14 Issue 2.

Bahadori, A., (2013): Pollution Control in Oil, Gas and Chemical Plants. Cham: Springer.

Basrur, S. V., (2000): Health Effects of Noise. City of Toronto, Toronto: Toronto Public Health.

De Muer T. and Botteldooren D. (2003): Uncertainty in Noise Mapping: Comparing a Probabilistic and a Fuzz Set Approach. T. Bilgi, et al. (Eds.): IFSA 2003, LNAI 2715, pp. 229-236, 2003.

Debnath, D., Nath, S.K and Barthakur, N.K (2012): Environmental Noise Pollution in Educational Institutes of Nagaon Town, Assam, India. Global Journal of Science Frontier Research - Environment and Earth Sciences. Vol. 12, Issue 1, Version 1.0, Year 2012.

Goines, L. and Hagler, L. (2007): Noise Pollution a Modern Plague. Southern Medical Journal, Volume 100.

Kamel, W., (2008): Assessment and measurement of noise level generated by traffic flow. Case study: El Kornesh roadway - Alexandria, Egypt. Assiut University Bulletin for Environmental Researches, Volume 11 No. 2

Kanjo E (2010): NoiseSPY: A Real-Time Mobile Phone Platform for Urban Noise Monitoring and Mapping. Mobile NetwAppl 15:562-574.

Kluijver de Henk and Stoter, J., (2003): Noise mapping and GIS: optimizing quality and efficiency of noise effect studies. Computer, environment and urban systems. 27 (2003) $85-102$

Konstantinos, V. (2012): Airport environmental noise mapping and land use management as an environmental protection action policy tool. The case of the Larnaka International Airport (Cyprus). Science of Total Environment 424 (2012) 162-173.

Narender, S., and Davar, S. C., (2004): Noise Pollution - Sources, Effects, and Control. Delhi, India: Journal of Human Ecology.

Nwafor, I. G., and Menkiti, A. I., (2015): Noise Levels, their health effects on humans in PortHarcourt. Nigeria: Journal of Nigerian Environmental Society (JNES), Vol. 9 No. 1.

Obiefuna, J. N., Bisong, F. E and Ettah, E. B. (2013): A GIS analysis of noise islands in Calabar metropolis, Nigeria. Journal of environment and earth science; Volume 3, number 12.

Omubo-Pepple, V. B., Briggs-Kamara, M. A., and Tamunobereton-ari, I., (2010): Noise Pollution in Port Harcourt Metropolis: Sources, Effects and Control. Working and Living Environmental Protection, Volume 7.

Oyedepo, S. O., (2013): Development of noise map of Ilorin metropolis, Nigeria. International Journal of Environmental Studies.

Song, X. D., Li, Q. and Wu, D. J., (2016): Investigation of rail noise and bridge noise using a combined 3D dynamic model and 2.5D acoustic model. Applied Acoustics, Volume 109.

WHO (1999): Guidelines for Community Noise, World Health Organization, Switzerland. 
British Journal of Environmental Sciences

Vol.10, No.1, pp. 13-24, 2022

ISSN 2054-6351 (print),

ISSN 2054-636X (online)

Wiebe, A., (2012): Anomalous Data of END noise mapping for major roads on the website of the European Environmental Agency, www.eea.europa.eu, Elsevier Ltd.

World Health Organization (2015): Make Listening Safe. WHO/NMH/NVI/15.2.

Yilmaz G, Hocanli H (2006): Mapping of Noise by Using GIS in Sanliurfa. Environmental Monitoring Assessment.

Zimmerman, T and Robson, Christine (2011): Monitoring Residential Noise for Perspective Home Owners and Renters. K. Lyons, J. Hightower, and E.M. Huang (Eds.): Pervasive 2011, LNCS 6696, pp.34-49, 2011. Springer-Verlag Berlin Heidelberg 2011. 